\title{
Phenotypic and Genotypic Characterization of Multi Drug Resistant E.coli Isolated from Chickens
}

A.A.Abd El-Tawab ${ }^{1}$, W.M.M. Hassan ${ }^{2}$, F.R.El-Seedy ${ }^{3}$ and H.Abdel-Satar ${ }^{2}$

${ }^{1}$ Bacteriology, Immunology and Mycology Dept., Faculty of Veterinary Medicine, Benha Univ., Benha, Egypt

${ }^{2}$ Reference Laboratories for Veterinary Quality control on poultry production, Animal Health Research Institute, Egypt

${ }^{3}$ Bacteriology, Immunology and Mycology Dept., Faculty of Veterinary Medicine, Beni Suif Univ., Beni Suif, Egypt

E-Mail: Ashraf.awad@fvtm.bu.edu.eg

\begin{abstract}
This study was performed on 1284 chicken came from 77 poultry farms layers, broilers, grandparents, broiler breeder at Giza and Qalubia governorates for E. coli infection. Samples were taken from these chickens (liver, intestine and yolk sac) after clinical and post mortem examination for morphological changes. The result revealed that, E. coli was isolated from 1204 positive samples (93.7\%) represented as 40 (100\%) from grandparents, 360 (90\%) from broiler breeder,100 (71.4\%) from layers and 704 (100\%) from broiler. By using polyvalent \& monovalent anti sera, these isolates were characterized for 18 different serogroups, most common detected serogroups is $\mathrm{O}_{158}, \mathrm{O}_{125}, \mathrm{O}_{119}, \mathrm{O}_{114}$ and $\mathrm{O}_{44}$ while there is 11 isolates are untypable. Antimicrobial susceptibility test by the disk diffusion method was performed in accordance with NCCLS (2008) for different 7 anti-microbial rugs (sulfamethazole, streptomycin, ciprofloxacin, enrofloxacin, tetracycline, trimethoprime and ampicillin). The results show that isolates were resistant to tetracycline and sensitive to ciprofloxacin. Eighty nine percent of isolates are multi drug resistant E. coli (resistant to 2 or more anti-microbial drug). In this study 20 isolates from total $73 \mathrm{E}$. coli isolates was examined for presence of resistance genes, the results revealed that: prevalence the gene aac $\left(6^{\prime}\right)$-Ib-cr for ciprofloxacin and enrofloxacin resistance in $45 \%$ of isolates, the prevalence of the bla $\mathrm{T}_{\mathrm{TEM}}$ gene $\beta$ - lactem resistance gene was detected in $80 \%$ of isolate, the prevalence of the tetA and sul1 genes tetracycline and sulfamethazole resistance genes was detected in $75 \%$ of isolates.
\end{abstract}

Keywords: Chickens, E.coli, Genotypic, Multi drug resistant, Phenotypic.

\section{Introduction}

E. coli is a member of the family Enterobacteriaceae, which may constitute a great hazard to poultry industry causing high mortality, loss of weight and reduction of egg production[3]. E. coli infection is one of the serious problems that cause a great threat to the profitability of birds' enterprises all over the word. Although E. coli is a normal inhabitant of the intestinal tract of birds, under the influence of predisposing factors, like inadequate and faulty ventilation, overcrowding, hunger, thirst, extremes of temperatures and low vitality[15]. E. coli strains classified by [19] into three major groups: commensal strains, intestinal pathogenic strains, and extra-intestinal pathogenic E. coli (ExPEC) strains. The species of E. coli are serologically divided into serogroups and serotypes on basis of their antigenic composition (somatic or $\mathrm{O}$ antigens for serogroups and flagella or $\mathrm{H}$ antigens for serotypes). Many strains express a third class of antigens (capsular or $\mathrm{K}$ antigens)[7]. Antimicrobial therapy is an important tool in reducing both the incidence and mortality associated with avian colibacillosis. However, resistance to existing antimicrobials is widespread and of concern to veterinarians [4]. This increasing resistance has received considerable national and international attention. Assessment of antimicrobial resistance of E. coli at molecular level is a useful tool for understanding the contribution of genetic elements responsible for developing and dissemination of resistance in bacteria [1]. The aim of the current work was designed to investigate the phenotypic and genotypic characters of multi drug resistant E. coli isolated from poultry.

\section{Materials and methods \\ 2.1 Sample collection}

The examined birds submitted to the Reference Laboratory for Veterinary Quality Control on Poultry Production, Dokki, to be examined for the presence of E. coli infection. 1284 chicken were examined. The samples collected from different organs (intestine, yolk-sac and liver). The examined organs will collected aseptically to prevent cross contamination. This included the use of sterile sampling materials (bags, spatula) wearing disposable gloves. The collected samples were cultured within a time limit, which did not exceed 24 hours from collection.

\subsection{Bacteriological examination}

Bacterial culture was prepared within $24 \mathrm{hr}$ after collecting samples, from (liver, yolk sac and intestine) and a ready cultivated under complete aseptic condition onto MacConkey agar then E.M.B. (Ethylene methylene blue). The plates were incubated at $37^{\circ} \mathrm{C}$ for $24-48$ hours and then examined for the characteristic E. coli colonies. Indole, Methyl red, Voges- Proskauer and Simons citrate (IMVIC) tests were performed with the 
colonies that showed growth characteristic of E.coli.

\subsection{Serotyping of E.coli isolates}

E.Coli isolates were serotyped by slide agglutination test according to [22] using standard e.coli antisera ( SIFIN AND DENKA SEIKEN COMP) .

\subsection{Antimicrobial susceptibility test}

Antimicrobial susceptibility test was assayed by the disc diffusion method NCCLS (2008). Multidrug resistance (MDR) isolates are defined as that isolate resistance to two or more anti-microbial drug. The anti-microbial disc used were sulfamethazole, streptomycin, ciprofloxacin, enrofloxacin, tetracycline, trimethoprim and ampicillin. Susceptibility and resistance were determined according to the interpretation criteria to E. coli (ATCC No. 25922) established by
Clinical Laboratory Standards Institute (CLSI) standard.

2.5 Conventional PCR technique for detection of anti-microbial resistance genes in isolated E.coli isolates

\subsubsection{DNA extraction}

DNA extraction was performed using the QIAamp DNA Mini kit (Qiagen, Germany, GmbH Catalogue no.51304). Oligonucleotide Primer. used were supplied from Metabion (Germany) are listed in Table (1) 2.5.2. PCR amplification: According to the instruction of the kit (Emerlad, Japan) primers were utilized in a $25-\mu 1$ reaction containing $12.5 \mu \mathrm{l}$ of EmeraldAmp Max PCR Master Mix (Emerland, Japan), $1 \mu 1$ of each primer of $20 \mathrm{pmol}$ concentrations, $4.5 \mu \mathrm{l}$ of DEPC water, and $6 \mu \mathrm{l}$ of template. The reaction was performed in a Biometra thermal cycler.

Table (1) Examined genes and its related Primers sequence concerning amplicon sizes and references

\begin{tabular}{lccc}
\hline Target gene & \multicolumn{1}{c}{ Primers sequences } & Amplicon size (bp) & Reference \\
\hline aac(6')-Ib-cr & $\begin{array}{l}\text { CCCGCTTTCTCGTAGCA } \\
\text { TTAGGCATCACTGCGTCTTC } \\
\text { bla }\end{array}$ & $113 \mathrm{bp}$ & Lunnet al., 2010 \\
tetA(A) & $\begin{array}{l}\text { ATCAGCAATAAACCAGC } \\
\text { CCCGAAGAACGTTTC }\end{array}$ & $516 \mathrm{bp}$ & Colom et al., 2003 \\
sul1 & $\begin{array}{l}\text { GGTTCACTCGAACGACGTCA } \\
\text { CTGTCCGACAAGTTGCATGA } \\
\text { CGGCGTGGGCTACCTGAACG } \\
\text { GCCGATCGCGTGAAGTTCCG }\end{array}$ & $576 \mathrm{bp}$ & Randall et al. 2004 \\
\hline
\end{tabular}

\subsubsection{Analysis of the PCR products}

[25]: The products of PCR were separated by electrophoresis on 1-\% agarose gel (Applichem, Germany, GmbH) in $1 \mathrm{x}$ TBE buffer at room temperature using gradients of $5 \mathrm{~V} / \mathrm{cm}$. For gel analysis, $15 \mu \mathrm{l}$ of the products was loaded in each gel slot. GeneRuler 100 -bp Ladder (Thermo scientific), was used to determine the fragment size. The gel was photographed by a gel documentation system (Biometra BDA digital) and the data was analyzed through computer software.

\section{Results}

The results of the microscopical identification of the suspected isolates showed Gram negative, non sporulated, straight rods. Growth on EMB agar colonies showed metallic sheen and give characteristic pink colonies. The results of biochemical identification gave the biochemical characteristic. The incidence of E. coli recovered from A total number of 1284 chickens from different farms in Giza and Qalubia are showed in Table (2).

The serotyping of the isolated strains revealed 73 E. coli isolates recovered from different samples, 62 strains were identified serologically belonged to 18 different serogroups. The most commonly detected E. coli serogroups isolated from different organs of chickens were $\mathrm{O}_{158}, \mathrm{O}_{125}$, $\mathrm{O}_{91}, \mathrm{O}_{114}, \mathrm{O}_{119}, \mathrm{O}_{44}$, while11 strains haven't been typed as shown in Table (3) From Table (4) it clears that the highest rate of resistance was shown against tetracycline group of Antibiotic, which was about $98.3 \%$ of isolate followed by $91.8 \%, 73.9 \%, 69.9 \%$, $58.9 \%$ of isolates were resistant to sulfamethazole and ampicillin, streptomycin, trimethoprim and enrofloxacin, and ciprofloxacin respectively. The examination of the twenty isolates for most represented antibiotic resistant genes by PCR aac $\left(6^{\prime}\right)-\mathrm{Ib}-\mathrm{cr}$, bla $\mathrm{TEM}$, tetA(A) and sullgenes revealed different percentage as shown in fig (1-4).

Table (2) Incidence of E.coli in different chicken flocks

\begin{tabular}{lccc}
\hline \multirow{2}{*}{ Types of examined chickens } & \multirow{2}{*}{ Number of examined farms } & \multicolumn{2}{c}{ Incidence of isolation } \\
\cline { 2 - 4 } & & No of positive farms & \% \\
\hline Grand parents & 2 & 2 & 100 \\
Broiler breeder & 20 & 18 & 90 \\
layers & 7 & 5 & 71.4 \\
broiler & 48 & 48 & 100 \\
total & 77 & 73 & 93.7 \\
\hline
\end{tabular}


Table (3) Different serotypes of isolated E.coli

\begin{tabular}{lcc}
\hline The E. coli serotype & Number of positive isolates /73 & Percentage of positive \% \\
\hline O158 & 13 & 17.8 \\
O125 & 7 & 9.5 \\
O91 & 5 & 6.8 \\
O114 & 5 & 6.8 \\
O119 & 3 & 4.1 \\
O44 & 3 & 4.1 \\
O27 & 2 & 2.7 \\
O78 & 3 & 4.1 \\
O25 & 3 & 4.1 \\
O103 & 2 & 2.7 \\
O26 & 2 & 2.7 \\
O111 & 1 & 1.4 \\
O127 & 1 & 1.4 \\
O86 & 1 & 1.4 \\
O169 & 1 & 1.4 \\
O8 & 1 & 1.4 \\
O63 & 1 & 1.4 \\
O157 & 1 & 1.4 \\
Un-typable & 11 & 15 \\
Total serotypes & 62 & 84.9 \\
\hline
\end{tabular}

Table (4) The percentage of antimicrobial resistance by disc diffusion method

\begin{tabular}{lccccccc}
\hline Reaction of examined strains & Sulfamethazole & Strept., & Tetra., & Trime., & Cipro., & Enro., & Ampi., \\
\hline Sensitivitg & 6 & 19 & 1 & 22 & 30 & 22 & 6 \\
Resistance & 67 & 54 & 72 & 51 & 43 & 51 & 67 \\
Percent of resistance & $91.8 \%$ & $73.9 \%$ & $98.3 \%$ & $69.9 \%$ & $58.9 \%$ & $69.9 \%$ & $53 \%$ \\
\hline
\end{tabular}

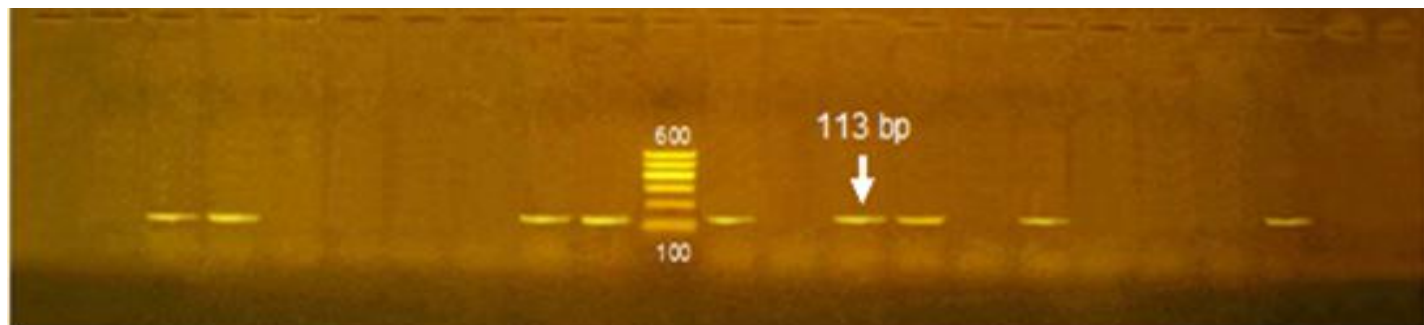

Fig (1) The prevalence of aac(6')-Ib-cr in $45 \%$ of isolates in isolates $(2,6,8,9,11,12,13,17,18)$

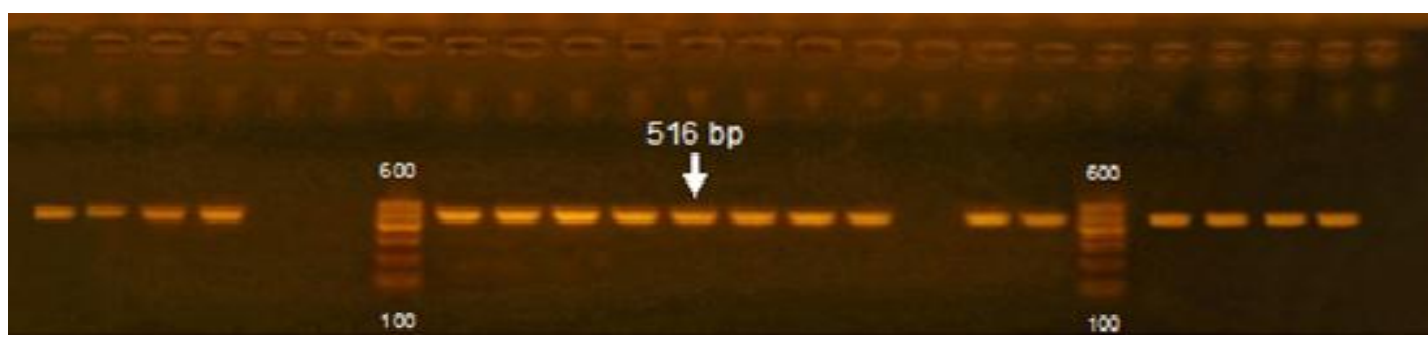

Fig (2) Show the prevalence of blaTEM gene in 17 (85\%) of isolates $(1,2,3,4,5,6,9,10,11,12,13,14,16,18,19 \& 20)$

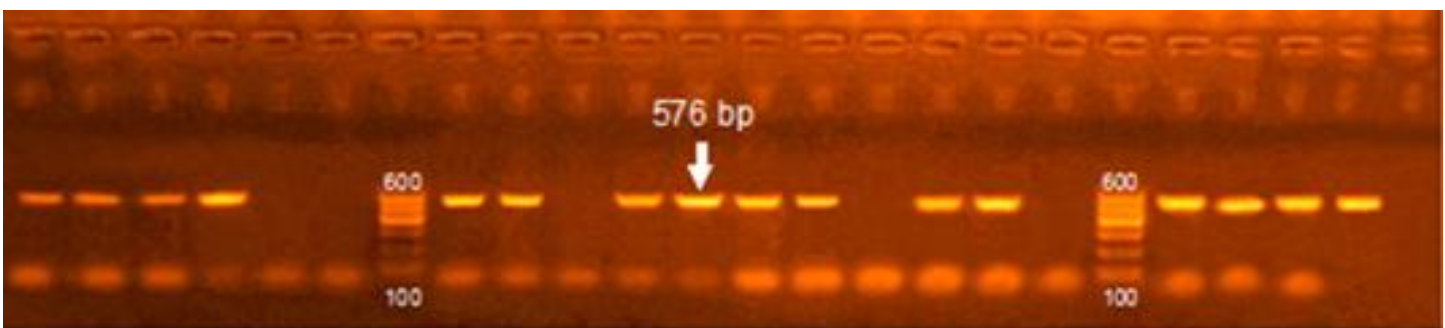

Fig (3) Show the prevalence of tetA GENE IN 15 (75\%) OF ISOLATES IN ISOLATES $(1,2,3,5,6,8,9,10,11,13,14,17,18,19,20)$ 


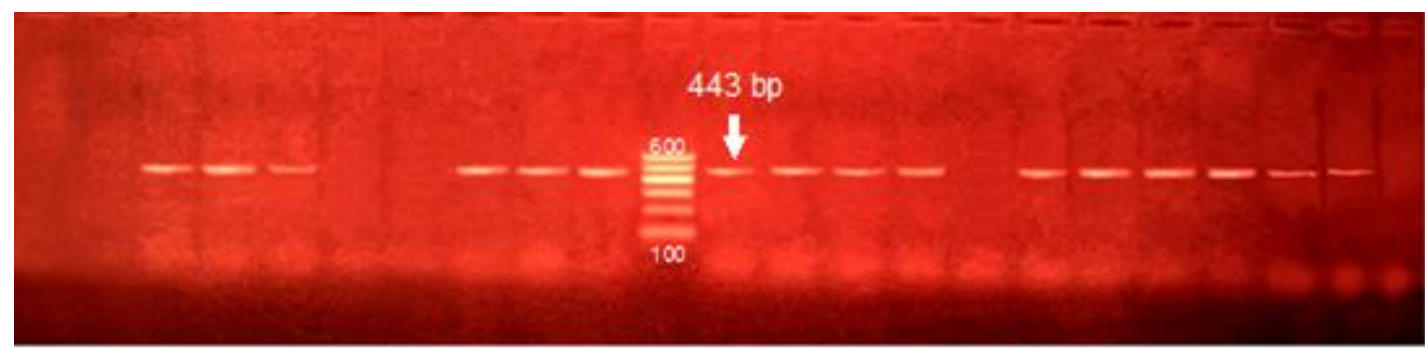

Fig (4) Show the prevalence of sull gene in $15(75 \%)$ of isolates in isolates

$(1,2,3,4,5,6,8,9,10,11,12,13,16,17,18)$

The highest prevalence appeared for the bla $\mathrm{TEM}_{\mathrm{TEM}}$ gene $\beta$ - lactem resistance gene $16(80 \%)$ followed by tetA (A) gene and the sul1 gene which was detected in $15(75 \%)$ for each. And lastly aac $\left(6^{\prime}\right)$ Ib-cr was $9(45 \%)$.

\section{Discussion}

Colibacillosis is an economically important disease, which is prevalent throughout the world [16]. E.coli has been implicated in a variety of diseases in poultry such as colisepticaemia, coligranuloma, air sacculitis, peritonitis, pericarditis, omphalitis and oophoritis, accounting for about 5-50\% mortality in poultry flocks [26] and perihepatitis, cellulitis, air sacculitis, or swollen head syndrome $[10,6]$ in this study the incidence of E.coli in broiler and broiler breeder and grandparents is higher than in layers, these results agree with [21] who stated that the percentages of resistant E.coli were significantly higher in turkeys and broilers than in the laying-hen population.

In this study the incidence of E. coli was $93.7 \%$, Also higher incidence $81.46 \%$ was reported by [27] and an incidence of $88.2 \%$ was mentioned by [12] . On the other side, lower incidence $34.3 \%$ was reported by [28]. The variations in the prevalence rates of E. coli in cases of diarrhea and septicemia may be due to the difference in the pathogenicity, virulence of the strains, the severity of the cases and the immunological status of the host.

The species of E. coli are serologically divided in serogroups and serotypes on basis of their antigenic composition (somatic or $\mathrm{O}$ antigens for serogroups and flagella or $\mathrm{H}$ antigens for serotypes) [13] . Many strains express a third class of antigens (capsular or K antigens) [7]. More than 1000 E. coli serotypes have been reported but only small percentages have been implicated in poultry diseases [9].

In this study 62 strains can be identified serologically. They belonged to 18 different serogroups. The most commonly detected E. coli serogroups isolated from different organs of chickens were $\mathrm{O}_{158} \quad(16.4 \%), \quad \mathrm{O}_{125} \quad(9.5 \%)$, $\mathrm{O}_{91}(6.8 \%), \mathrm{O}_{114}(6.8 \%), \mathrm{O}_{119}(4.1 \%), \mathrm{O}_{44}(4.1 \%)$, while11 strains were Not typed. These results go hand to hand with the previous [20]; [5,14] that reported that serogroups $\mathrm{O}_{44}, \mathrm{O}_{158}, \mathrm{O}_{114}$ and $\mathrm{O}_{91}$ were traditionally associated with colibacillosis in poultry.

In this study, the antibiogram was carried out against different E. coli serotypes using 7 different antibiotics. The results revealed that, about $89 \%$ of the isolates are multi-resistant as they resist at least 3 antibiotics, this resistance pattern, the so called multiple antimicrobial resistance $(>$ or $=3$ antimicrobials) of E.coli recovered from poultry was reported by $[8,11,24,18]$.

These finding agreed with that reported by [4,9] who attributed the development of drug resistance to frequent usage of drugs in veterinary practices at suboptimal concentrations or may be due to usage of antibiotics to control the infectious diseases [2].

In our study the isolates show high resistance to tetracycline by using disc diffusion about $93.8 \%$. However, PCR test revealed lower percentage of 75 $\%$ of isolates carry the resistance gene (tetA). the results agree with [17] that studied the actual frequency of antimicrobial resistance in fecal Escherichia coli (E. coli) isolated from chicken at the phenotype level and to determine the genetic background for the two major resistance phenotypes (streptomycin and tetracycline). One hundred and nine E. coli isolates were higher resistant to ampicillin (68.8\%) streptomycin $(60.6 \%)$, ciprofloxacin $(65.1 \%)$, and tetracycline (96.3\%). Resistant gene tetA was amplified while the tetA 22 was $20.2 \%$. Also they insured that the significant differences could be observed between isolates not only at the phenotype level but also at the genotype level.

The resistance to ciprofloxacin antibiotics was about $58.9 \%$ by using disc diffusion. On other hand the PCR test results for the aac $\left(6^{\prime}\right)$-Ib-cr gene was $(45 \%)$ for ciprofloxacin and enrofloxacin resistance (Fig1). The obtained results during this study was confident with some results achieved by [23] who showed high rates of resistance to quinolones from different parts of the world. In China, for example, more than $50 \%$ of the clinical strains of E. coli isolated during 1997-1999 were resistant to ciprofloxacin. While [22] observed that 198 avian E. coli isolates from Shandong, China were resistant to enrofloxacin $99 \%$, ciprofloxacin $100 \%$, norfloxacin $\quad 100 \%, \quad$ amoxicillin/clavulanic 
acid87.4\%, ampicillin 99.5\%, gentamicin $97 \%$ and amikacin $27.8 \%$. .

\section{References}

[1] J.Angulo, N.Nargund, C.Chiller, Evidence of an association between use of anti-microbial agents in food animals and anti-microbial resistance among bacteria isolated from humans and the human health consequences of such resistance. J. Vet. Med., vol.51, p.374, 2004.

[2] M.A.Akond, S.Alam, S.M.R.Hassan, M.Shirin, Antibiotic resistance of Escherichia coli isolated from poultry and poultry environment of Bangladesh. Internet J. Food Saf., vol.11, p.19, 2009.

[3] P.K.Bandyopadhay, R.G.Dhawedkar, E. coli salpingoperitonitis in poultry. Indian Vet. J., vol.61, pp.348-349, 1984.

[4] J.E.Blanco, M.Blanco, A.Mora, W.H.Jansen, V.V.Garcia, M.L.Azquez, J.Blanco, Serotypes of E. coli isolated from septicemia in chickens in Galicia (northwest Spain). Vet. Microbiol. Vol.3, pp.229-235, 1998.

[5] J.F.Bosch, J.H.Hendricks, I.Gladigan, H.M.Willimes, PK.Storm, F.K.Graaf, Van-denBosch, F.K.Graaf, Identification of fimbriae on chicken E. coli strains. Infect. Immune, vol.61(3), pp.800-806, 1993.

[6] J.Barnes, L.K.Nolan, J.F.Vaillancourt, Colibacilliosis In Y.M.Saif, A.M.Fadly (Eds.), Diseases of poultry. Ames, Iowa: Blackwell Publishing, 12. ed., pp.691-732, 2008.

[7] L.C.Compos, M.R.Franzolin, L.R.Trabuls, Diarrhea genic E. coli categories among the traditional entero pathogenic E. coli Oserogroups. Mem. Inst. Oswald Cruz; vol.99 (6), pp.545-552, 2004.

[8]A.Chandran, A.A.Hatha, S.Varghese, K.MonySheeja, Prevalence of multiple drug resistant E. coli serotypes in a tropical estuary, india. Microbes, Environ., vol.23 (2), pp.153158, 2008.

[9]S.S.Cloud, J.K.Rosenberger, P.A.Fries, R.A.Wilson, E.M.Odor. In vitro and in vivo characterization of avian E. coli 1-serotypes, metabolic activity and antibiotic sensitivity. Avian Dis., vol.29(4), pp.1084-1093, 1985.

[10] F.Dho-Moulin, M.Fairbrother, Avian pathogenic E. coli (APEC). Vet. Res., vol.30(23), pp.299-316, 1999.

[11] M.Da Coasta, M.Oliveira, A.Bica, P.VazPires, Bernard. Antimicrobial resistance in Enterococcus spp. and E. coli isolated from poultry feed and feed ingredients. Vet. Microbiol., vol.120(1-2), pp.122-31, 2007.

[12] S.N.EL-Sukhon, M.Asad, M.Al-Attar,. Studies on the bacterial etiology of air sacculities of broilers in Northern and Middle Jordan with special reference to E. coli. Avian Dis., vol.6(3), pp.605-612, 2002.
[13] P.Griffin, R.Tauxe, The Epidemiology of Infections Caused by Escherichia coli $\mathrm{O}_{157}: \mathrm{H}_{7}$, Other Enterohemorrhagic E. coli, and the Associated Hemolytic Uremic Syndrome," epidemiological review, vol.13, pp.60-98, 1999.

[14] W.B.Gross, Colibacillosis diseases of poultry, Editors Calnek, B.W. et.al. Lowa State Univ. Press, Ames. Lowa State Univ, 9thEd, pp.38144, 1991.

[15] L.Kaul, L.P. a. Kaul, N.M.shah, An outbreak of colibacillosis in chicks at an organized poultry farm under semi-arid zone of north Gujarat. Indian. Vet. J., vol.69, pp.373374, 1992 .

[16] L.Margie, A.Lawrence, A Laboratory Manual for the isolation and identification of avian pathogens: American Association of Avian Pathologists, Athens, GA, 4th ed., 1999.

[17] Moon Ho Jang, 'Jae Keun Cho, iDongMiKwak, 'Gil-Jae Cho; 'Young Ju Lee. Antimicrobial Resistance and Resistance Gene Determinants of Fecal Escherichia coli Isolated from Chicken. Korea Journal of Animal and Veterinary Advances vol.10 (24), pp.33083311, 2011.

[18] Zhang, Wang-Da Cheng, Yong-Guan Zhu . Abundance and Diversity of Tetracycline Resistance Genes in Soils Adjacent to Representative Swine Feedlots in China Environ. Sci. Technol., vol.44(18), pp.69336939, 2010.

[19] T.RUSSO, J.JOHNSON, E.PRUKNER, frequency and epidemiological significance of virulent E. coli strains in dead poultry in yugoslavia and sensitivity to antimicrobial agents. vet. Archival, vol.56(5), pp.227-237, 2002.

[20] Suwanichkul, Panigrahy. Diversity of piles subunits of E. coli isolated from avian species. Avian Dis, vol.32(4), pp.822-825, 1988.

[21] E.Van den Bogaard, N.London, C.Driessen, E.Stobberingh, Antibiotic resistance of fecal Escherichia coli in poultry, poultry farmers and poultry slaughterers. J. Antimicrob. Chemother., vol.47, pp.763-771, 2001.

[22] L.Xia, L.Li, C.Wu, Y.Liu, X.Tao, L.Dai, Y.Qi, L.Lu, J.Shen, A survey of plasmid mediated fluoroquinolone resistance genes from Escherichia coli isolates and their dissemination in Shandong, China. Foodborne Path. Dis., pp.0378, 2009.

[23] H.Wang, J. L.Dzink-fox, M.chen, S.B.levy, Genetic characterization of highly fluoroquinolone resistant clinical Escherichia coli strains from China: Role of acrR Mutations. Antimicrob. Agents Chemother., VOL.24(5), PP.1515-1521, 2001.

[24]S.Zhao, J.Maurer, S.Hubert, J.Villena, P.Mcdermott, J.Meng, S.Ayers, L.English, D.White, Antimicrobial susceptibility and 
molecular characterization of avian pathogenic Escherichia coli isolates. Veterinary Microbiology vol.107(3-4), pp.215-224,2005.

[25] J.Sambrook, E.F.Fritschi and T.Maniatis Molecular cloning: a laboratory manual, Cold Spring Harbor Laboratory Press, New York, 1989.

[26] P.Roy, V.Purushothaman, A.Koteeswaran, A.S.Dhillon (2006). Isolation, Characterization, and Antimicrobial Drug Resistance Pattern of Escherichia coli Isolated from Japanese Quail and their Environment. J. Appl. Poult. Res., vol.15, pp.442-446, 2006.

[27] E.Prukner, Frequency and epidemiol-ogical significance of virulent E. coli strains indead poultry in Yugoslavia and sensitivity toantimicrobial agents.Vet.Archival.vol.56(5), PP.227-23, 1986.

[28] N.Sripoernomo, S.L.Suterma, M.Jeanuri, R.Iskanda, Colibacillosis in poultry in Indonesia. Isolation and serotyping of E.coli from Poultry farms in java and Bali. Penyakit. Henan, vol.24(43), pp.33-38, 1992. 